Article

\title{
Thermal Performance Analysis of a Solar Reactor Designed for Syngas Production
}

\author{
Yabibal Getahun Dessie ${ }^{1} \mathbb{D}$, Bachirou Guene Lougou ${ }^{1,2, * \mathbb{C}}$, Qi Hong ${ }^{1, * \mathbb{C}}$, Tan Heping ${ }^{1}$, \\ Zhang Juqi ${ }^{1}$, Gao Baohai ${ }^{1}$ and Islam Md Arafat ${ }^{1}$ \\ 1 School of Energy Science and Engineering, Harbin Institute of Technology, Harbin 150001, China; \\ get_yabibal@yahoo.com (Y.G.D.); tanheping@hit.edu.cn (T.H.); zhangjq_hit@163.com (Z.J.); \\ 18846753664@163.com (G.B.); aisadaf7@yahoo.com (I.M.A.) \\ 2 MIIT Key Laboratory of Critical Materials Technology for New Energy Conversion and Storage, \\ School of Chemistry and Chemical Engineering, Harbin Institute of Technology, Harbin 150001, China \\ * Correspondence: 15bf02043@hit.edu.cn (B.G.L.); qihong@hit.edu.cn (Q.H.)
}

Received: 2 June 2020; Accepted: 29 June 2020; Published: 2 July 2020

check for updates

\begin{abstract}
The design elements considered during the construction of a thermochemical reactor determine its thermal performance. This current study investigated the effect of design elements, such as boundary layer thickness, insulating materials for the outlet tube design and fluid inlet locations of the frustum, on the thermal performance of a proposed syngas production reactor with incident radiation heat transfer through quartz glass. The $\mathrm{P}_{1}$ radiation approximation model and fluid flow in the shallow path were integrated into a proposed radiation model. The result indicated that inlet mass flow rates from $5 \times 10^{-4}$ to $14 \times 10^{-4} \mathrm{~kg} / \mathrm{s}$ increased the temperature in the cavity and the outlet. The fluid inlet located at the top of the quartz glass edges was found to have better thermal performance and maximum average outlet temperature. Insulation for fluid inlets tube above the quartz glass edges of the frustum was very important for the prevention of radiation loss through quartz glass and sedimentation of fluid particles around the quartz glass edge, and the facilitation of fast heat transfer towards the internal part of the reactor. The outlet that was a tube designed using an aluminum oxide-type insulator with a $50 \mathrm{~mm}$ boundary layer thickness was found to increase the average outlet temperature of the reactor. This study revealed that fluid entry and exit locations on the frustum and proper fluid outlet design were critical for the thermal performance analysis of the solar thermochemical reactor for heat transfer with quartz glass. Findings from this study will be of relevance to chemical and power engineering sectors, as well as academia.
\end{abstract}

Keywords: incident radiation; thermal performance; thermochemical reactor; heat transfer; reactor tube design

\section{Introduction}

The global climate is increasingly changing due to increased emission of greenhouse gasses from the burning of fossil fuels. This phenomenon has been shown to have adverse impact on human life and nature. The use of renewable sources of energy becomes imperative at this time, as they are readily available to mankind, economically sustainable and provide cleaner energy, as opposed to nonrenewable energy sources.

Syngas is a promising renewable energy with potential application in power generation. It can be produced through the application of concentrated solar power (CSP) in conjunction with a thermochemical reactor. In syngas production, the design of the reactor is important for effective and efficient collection, processing and storage of solar energy [1-3]. Other factors that affect the thermal performance of a reactor during syngas production include geometry, thermal insulation, 
input materials, and inlet parameters. In the process of solar heat transfer, concentrated solar energy that is absorbed directly from the sun passes through a quartz glass into the reactor with the help of an inlet fluid. This energy can be used directly for the production of electricity and syngas, as well as thermochemical storage through a chemical reduction and oxidation process. Reduction followed by oxidation and ionization with water molecules produces enough hydrogen, which can fulfill global energy demand [4-7]. High-temperature thermochemical processes are utilized in facilitating the chemical reduction process of metal oxide with the aim of gasification of high carbonate concentrate in synthesizing valuable fuels and chemicals by concentrating solar energy [1,8-16]. About 1200 to $1900 \mathrm{~K}$ can be used for the reduction of metal oxides depending on the type of input material $[12,17,18]$. Syngas chemical composition varies depending on the raw materials and the processes. Syngas produced by coal gasification generally consists of a mixture of $30-60 \%$ carbon monoxide, $25-30 \%$ hydrogen, $5-15 \%$ carbon dioxide, $0-5 \%$ methane. Syngas production is an endothermal process that requires high temperature $(\mathrm{T}>1173 \mathrm{~K})$ for its equilibrium.

The effect of geometric parameters on the thermal efficiency of a solar dish receiver was investigated by Wang and Siddiqui [19] and Suter et al. [20]. They developed pore-level engineering for microporous media to enhance the performance of solar-driven thermochemical fuel production. In order to optimize the volumetric air receiver efficiency of the reactor, Wu et al. [21] performed a numerical simulation of convective heat transfer between airflow and ceramic foams. In addition, a $\mathrm{P}_{1}$ approximation radiation model for the study of irradiative heat transfer was proposed by Cheng [22,23].

Different radiation models have been proposed to examine the radiation distribution in reactors. Wang et al. [24,25] and others developed different models [26-28] for radiative transfer in analyzing the thermal performance of porous solar media and the thermal transmission of solar reactor thermoacoustics for the production of syngas. In addition, radiation models have been proposed that can resolve sunlight intensity across all the participating media involved in the analysis of the thermal performance of solar reactors for syngas. Bellan et al. [29] developed a thermochemical reactor and demonstrated how radiation heat transfer is calculated by using a surface-to-surface (S2S) radiation model. They also analyzed the thermofluid flow, absorption efficiency and predicted the temperature distribution as a function of time. Lougou et al. [30-33] suggested that geometry is vital for effective uniform thermal distribution in a reactor and showed that inlet parameters such as velocity, pressure, radiation loss at radiation inlet region and aperture region have an impact on temperature drop and thermal performance of a thermochemical reactor. Peng et al. [34] studied heat transfer by using discrete element method (DEM)-based model simulations of thermal processes. Schrader et al. [35] proposed a $5 \mathrm{~kW}$ granular-flow reactor with aluminum-doped calcium manganite particles for solar thermochemical energy storage. Bellouard et al. [36] designed, simulated and studied a directly irradiated solar chemical reactor for hydrogen and syngas production from continuous solar-driven wood biomass gasification. They developed a new concept of a solar-spouted-bed reactor with continuous biomass injection in order to enhance heat transfer in the reactor, to improve gasification rates and gas yields by providing constant stirring of the particles and to enable continuous operation. Yong Shuai et al. [37] studied heat transfer analysis of a solar-driven high-temperature thermochemical reactor using NiFe aluminate reusable plastic containers. They analyzed how the reacting medium is affected by radiation heat transfer and how the heat distribution is supported in the production of oxygen and hydrogen in the reacting medium, which are facilitated by convective reactive gas moving through the medium's pores. 
According to abovementioned literature, there is ample knowledge on heat storage, thermochemical heat analysis and receiver cavity design regarding many factors and parameters that affect reactor thermal performance. There is no clear knowledge of the effect of outlet tube design, insulating layer thickness, insulation inlet tube above quartz glass at both sides of frustum edges when the inlet tube is located at the edge of the quartz glass in a reactor. Moreover, these parameters are reported to have significant effect on the thermal performance of a solar rector with respect to the heat applied through the quartz glass in a reactor. For example, Lougou et al. [32] studied the thermal performance of a syngas reactor and explained the importance of fluid inlets in avoiding solid deposition around the frustum region. However, the author did not study the effect of location of the fluid inlets on the thermal performance of the reactor. Bellouard et al. [36] used three fluid inlets on the frustum of a reactor but did not indicate the importance and location of these fluid inlets in the reactor. The authors used insulation above the quartz glass but did not discuss its impact on the thermal performance of the reactor.

Therefore, the objective of this current study is to simulate and study the effect of parameters on the thermal performance of a syngas reactor, such as the type of wall material, the type of external insulating material, the location of carrier gas inlets on the frustum, the insulation above the quartz at frustum edges and the insulation layer thickness for the outlet tube. In addition, optimal conditions for efficient heat transfer in the reactor are proposed.

\section{Methodology}

\subsection{Model Description}

The thermal simulation was done for the validation of the reactor design and the cavity dimensions. In achieving the uniform thermal temperature distribution and maximum outlet temperature in the reactor, COMSOL Multiphysics (Version 5.3, COMSOL Inc., Stokolem, Sweden) software was used by selecting suitable geometry and proper use of insulation thickness. The thermal performance of the reactor was analyzed with a $\mathrm{P}_{1}$ radiation model coupled with shallow channel approximation. This model was used to investigate the heat flux distribution along the reactor. The governing and other related basic thermodynamic equations were solved using finite element technique in the COMSOL Multiphysics 5.3 software. The objective of the simulation was to determine the maximum outlet temperature based on the available solar input in the outlet tube, to predict the temperature distribution profile in the reactor and to ascertain if high temperature could be reached for the needed application and if the dimensions are suitable to achieve the required outlet temperature.

Figure 1 shows the 2D schematic diagram of the proposed solar thermochemical reactor used for the numerical simulation. The boundary fields of the reactor are characterized by reactor inlets, wall and outlet. The wall was protected by a constant cold-wall temperature of $298 \mathrm{~K}$ (sections AK, MBE, FCL and GD in Figure 1); two opposite gas inlets (sections KM and GL in Figure 1), $0.375 \mathrm{~cm}$ in diameter, on the base of the quartz glass; one outlet (point EF in Figure 1) with a diameter of $0.75 \mathrm{~cm}$ and a $0.3 \mathrm{~cm}$ thick quartz glass. (section DN in Figure 1) and (section RA in Figure 1) denote radiation loss. All the walls were insulated by a high-temperature resistant metallic alloy aluminum oxide $(3.4 \mathrm{~cm})$. The boundary wall and frustum were made from a high-temperature resistant metallic FeCrAl alloy with a melting point close to $1800 \mathrm{~K}(0.4 \mathrm{~cm}$ thick and able to withstand up to $2000 \mathrm{~K}$, $35 \mathrm{~W} / \mathrm{m} \cdot \mathrm{K}$ thermal conductivity at $1600 \mathrm{~K}, 7100 \mathrm{~kg} / \mathrm{m}^{3}$ density, $800 \mathrm{~J} / \mathrm{kg} \cdot \mathrm{K}$ at $1600 \mathrm{~K}$ heat capacity and 0.7 emissivity). As shown in Figure 1, the cavity had a width of $4.5 \mathrm{~cm}$ and a height of $11.5 \mathrm{~cm}$, a receiver (section RN in Figure 1) with a diameter of $7.5 \mathrm{~cm}$ and aperture diameter of $2.1 \mathrm{~cm}$. Nitrogen was the carrier gas for the reactor. This gas works to sweep and remove particles deposited from the region of the receiver to the cavity. 


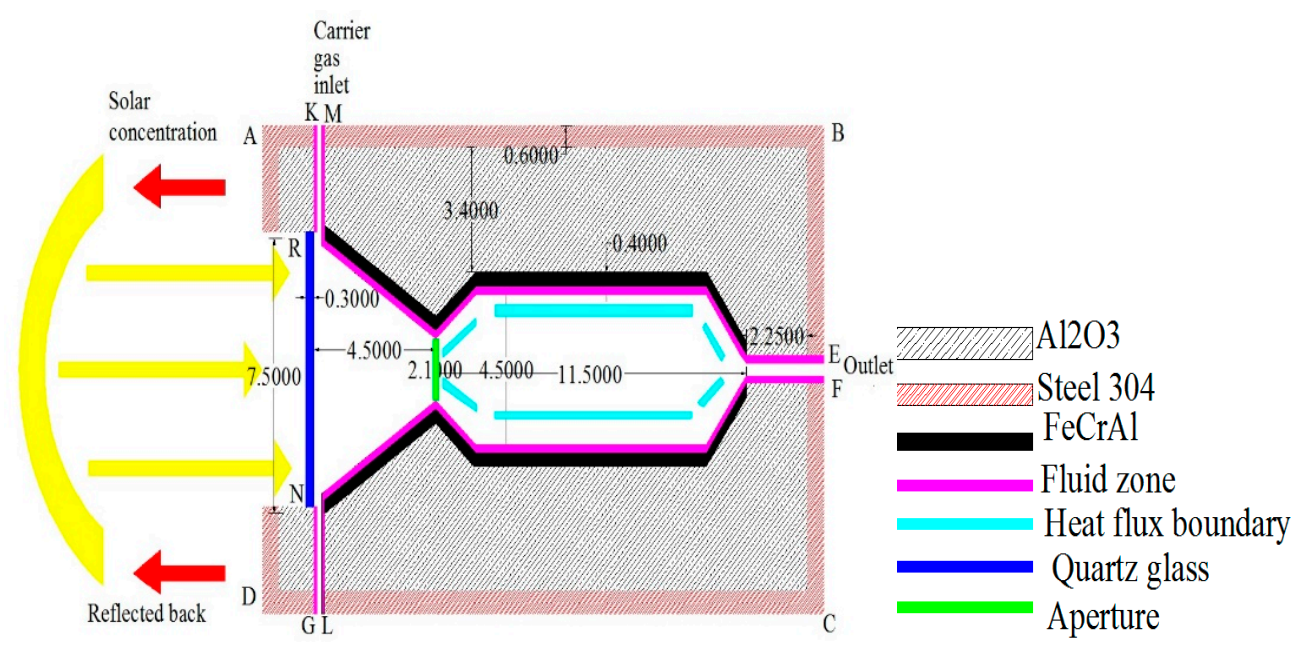

Figure 1. Schematic diagram of the proposed model for the heat storage reactor including the computational domain used for the simulation.

\subsection{Simulation Setup}

COMSOL Multiphysics 5.3 software was selected for the thermal performance and prediction of the outlet temperature for the proposed reactor. A 2D geometry was chosen the from the COMSOL application model wizard. A geometry was built using AutoCAD (version 16.0, Autodesk, Inc., San Rafael, CA, USA) software and was then imported into the graphics window. From the material tab, the wall materials were selected and added to the boundaries and domains of heat transfer in fluid and laminar flow nodes. From model builder, under the component heat transfer node, solid and liquids were selected, which were the domains of the reactor. The boundary conditions were selected. These boundary conditions were two opening boundaries: "opening boundary 1 " was for the outlet, and "opening boundary 2" was for the inlet. Three diffused surfaces were applied on the frustum and quartz glass edges. Two layer thicknesses were selected: one layer thickness $(0.4 \mathrm{~cm})$ was applied on the reactor wall, including the frustum edge, and the other layer thickness was applied for the quartz glass edge $(0.3 \mathrm{~cm})$. Four temperatures were selected: applied radiation temperature (T1) was $1600 \mathrm{~K}$, cooled-wall temperature (T2) was $283 \mathrm{~K}$ and applied at the external wall of the insulator edges, inlet temperature (T3) and outlet temperature (T4) were $293.5 \mathrm{~K}$ and $293.5 \mathrm{~K}$, respectively. From the heat transfer node, the radiation participation media was selected and added to the liquid domain, and for the physical model, surface-to-surface and radiation participating media were also added. From participation media, radiation discretization method was selected, followed by the selection of the $\mathrm{P}_{1}$ radiation model. In the laminar flow node, two inlets with $11 \times 10^{-4} \mathrm{~kg} / \mathrm{s}$ mass flow rates each and one outlet boundary with zero pressure were added. By default, the liquid was confined within a wall. From the laminar tab under the weakly compressible gases setting, parameters namely shallow channel approximation, reference channel thickness, reference temperature and pressure were selected and applied. Nonisothermal physics was selected and used for the coupling of the heat transfer in the liquid and laminar flow. This was followed by selection of the mesh, which was a user-controlled free triangular mesh. Applying all boundary conditions in Table 1 to Figure 1, and adjusting the time dependent simulation in the time check box to 0,1 and 90 , the work was stimulated for 90 min and the results were analyzed. 
Table 1. Boundary conditions.

\begin{tabular}{cccc}
\hline Section & Boundary Type & Mass Flow & Energy \\
\hline Inlet tube one (KM) & Laminar-Inlet & Mass flow rate & Temperature 293.15(K) \\
Inlet tub two (LG) & Laminar-Inlet & Mass flow rate (kg/s) & Temperature 273.15(K) \\
Irradiated walls or diffused surface & Walls & 0.0 & $q=e\left(G-s T^{4}\right)+q_{d}$ \\
(edges of the frustum) & Wall & 0.0 & $q=h\left(T_{\mathrm{a} m b}-T\right)$ \\
External Boundaries (AB, BC and CD) & Wall & 0.0 & $q=h\left(T_{\mathrm{a} m b}-T\right)+e_{e x t} s\left(T_{Y=}-T\right)$ \\
Quartz window (NR) & Pressure outlet & $\frac{\partial V_{i}}{\partial n}=0$ & $\frac{\partial T}{\partial n}=0$ \\
\hline
\end{tabular}

Variables $q, h, T_{\mathrm{a} m b}, T, e_{e x t}, s$ and $q_{d}$ are heat flux, heat transfer coefficient, ambient temperature, temperature, emissivity, Stefan-Boltzmann constant and diffused heat flux, respectively.

\subsection{Assumptions}

The following assumptions were made:

(a) The gas used in the simulation was nitrogen and assumed to be weakly compressible (0.01 absorption coefficient and zero scattering effect);

(b) Opaque gray diffused surface was neglected;

(c) The solar thermal energy distribution inside the reactor was assumed as a steady-state solver;

(d) The simulation was conducted by assuming that boundaries, radiate walls and the temperature flow in the cavity were uniform and not varied;

(e) The $\mathrm{P}_{1}$ radiation models selected for heat transfer were coupled with shallow channel approximation;

(f) The initial temperature at the beginning of the simulation was $293.15 \mathrm{~K}$ and this temperature included the walls, cavity and the nitrogen gas inside the reactor;

(g) The walls were made of zirconia $\left(\mathrm{ZrO}_{2} \mathrm{eY}_{2} \mathrm{O}_{3}\right)$ and $3 \mathrm{Al}_{2} \mathrm{O}_{3}-2 \mathrm{SiO}_{2}$ (mullite) solid (36\% porosity), and the wall thickness and emissivity were $0.4 \mathrm{~cm}$ and $\varepsilon=0.7$, respectively.

\subsection{Governing Equations}

To predict the instantaneous temperature distribution and the fluid flow inside the reactor, a numerical model was developed assuming that the flow was laminar and the continuity conservation equation, momentum conservation equation and energy conservation equation for the solar thermal energy reactor were calculated. Hence, the governing equations for the thermofluid flow inside the reactor are given by Equations (1)-(3) [29]:

$$
\begin{gathered}
\rho \frac{\partial u}{\partial t}+\nabla \cdot(\rho u)=0 \\
\rho \frac{\partial u}{\partial t}+\rho(u \cdot \nabla) u=-\nabla P+\nabla\left[\mu\left(\Delta u+(\nabla u)^{T}\right)-\frac{2}{3} \mu \nabla u\right] \\
\rho c_{p} \frac{\partial T}{\partial t}+\rho c_{p} u \cdot \nabla T=\nabla \cdot u(k \nabla T)
\end{gathered}
$$

where $\rho, u, P, \mu, k, T$ and $c_{p}$ are density, velocity vector, pressure, dynamic viscosity, thermal conductivity, temperature and specific heat, respectively. Equation (1) states the mass conservation, Equation (2) states the momentum conservation and Equation (3) is the energy conservation equation

The incident radiation flux intensity for $\mathrm{P}_{1}$ radiation models is calculated using Equation (4):

$$
Q r=\nabla \mathrm{q}_{\mathrm{r}}=\kappa\left(G-4 \pi \mathrm{I}_{b}(T)\right)
$$

where $\mathrm{Q}_{r}$ is the radiative heat source, $\mathrm{q}_{\mathrm{r}}$ is conductive heat flux, $\kappa s$ absorption coefficient, $I_{b}(T)$ is radiation intensity and $\mathrm{G}$ is incident flux. 
The heat equation is written as:

$$
\begin{gathered}
C_{p}\left(\frac{\partial T}{\partial t}+u \cdot \nabla T\right)+\nabla \cdot q=\kappa\left(G-4 \pi \mathrm{n} \sigma T^{4}\right)+\alpha_{p} T\left(\frac{\partial P}{\partial t}+u \cdot \nabla P\right)+\tau: \nabla u+Q \\
I_{b}(T)=\frac{n_{r}^{4} T^{4}}{\pi}
\end{gathered}
$$

where $\mathrm{n}_{r}, \tau$ and $\alpha_{\mathrm{p}}$ are the index of refraction, viscous tensor, and coefficient of thermal expansion, respectively.

The balanced radiation transfer equation are found in Equations (7)-(10) [22,23]:

$$
\frac{d I_{r, s}}{d s^{\prime}}=\nabla\left(I_{r, s}\right)=I_{b, r}-\left(\kappa+\sigma_{r, s}\right) I_{r, s}-\frac{\sigma_{r, s}}{4 \pi} \int_{4 \pi} I_{r, s^{*}}\left(s^{*}, s\right) \Phi d \Omega^{*}
$$

where $\kappa$ and $\sigma_{s}$ are the absorption and scattering coefficients, respectively.

The general radiation flux transfer in a medium can be described as:

$$
G=\int I(\Omega) d \Omega
$$

The heat source can be described by the following equations:

$$
\begin{gathered}
-\nabla\left(\nabla P_{1} \nabla G\right)=Q_{r} \\
D P_{1}=\frac{1}{3 \kappa+\sigma_{s}\left(3-\mathrm{a}_{1}\right)}
\end{gathered}
$$

where $\mathrm{a}_{1}$ is the linear Legendre coefficient of scattering phase function and $Q_{r}$ is the radiative heat source.

When the scattering model $\mathrm{a}_{1}=0$, Equation (10) becomes:

$$
D P_{1}=\frac{1}{3 \kappa+3 \sigma_{s}}
$$

for $\sigma_{s}=0$ and $D P_{1}=\frac{1}{3 \kappa}$, Equation (9) can be expressed as follows:

$$
\nabla\left(\nabla P_{1} \nabla G\right)=Q_{r}, \nabla \cdot\left(\frac{1}{3 \kappa} \nabla G\right)=\kappa G-4 \pi \varepsilon \sigma_{S B} T^{4}
$$

From Equation (4), it can be shown that the radiative heat transfer was added to the system, which can now be expressed as:

$$
-\nabla q_{r}=\kappa G-4 \pi \varepsilon \sigma_{S B} T^{4}
$$

\subsection{Boundary Conditions}

The applied physical parameters and boundary conditions are shown in Table 1 ; the inlets are located at the base of the quartz window and in opposite directions. The nitrogen gas flows at $1 \mathrm{~atm}$ with $293.15 \mathrm{~K}$, and $11 \times 10^{-4} \mathrm{~kg} / \mathrm{s}$ mass flow applied at each inlet. The thermal reactor was horizontally fixed and, as seen in Figure 1, the radiation temperature was applied to the quartz glass. The ambient surroundings behaved as a black body, and cold-wall temperature ( $298 \mathrm{~K}$ ) was applied on the boundaries (AB, $\mathrm{BC}$ and $\mathrm{CD}$ ). Table 1 also indicates the type of boundaries and applied conditions.

\subsection{Model Validation}

Figure 2 shows the temperature distribution of the proposed reactor compared to that of a conventional reactor [25]. The validation was computed from reference [25] for both $\mathrm{P}_{1}$ and the Rosseland approximation models. Comparing the models, as it can be seen from the Figure 2, 
both graphs almost overlap one another. This indicates that the $\mathrm{P}_{1}$ approximation radiation model can effectively analyze what was done in reference [25] with Rosseland approximation model. It was found that the maximum absolute error between both models was $1.99 \%$, indicating that the model utilized in this study was efficient. However, there were slight variations inside the reactor. This was possibly due to the differences in boundary conditions, geometry design and the type of mesh used during the simulation.

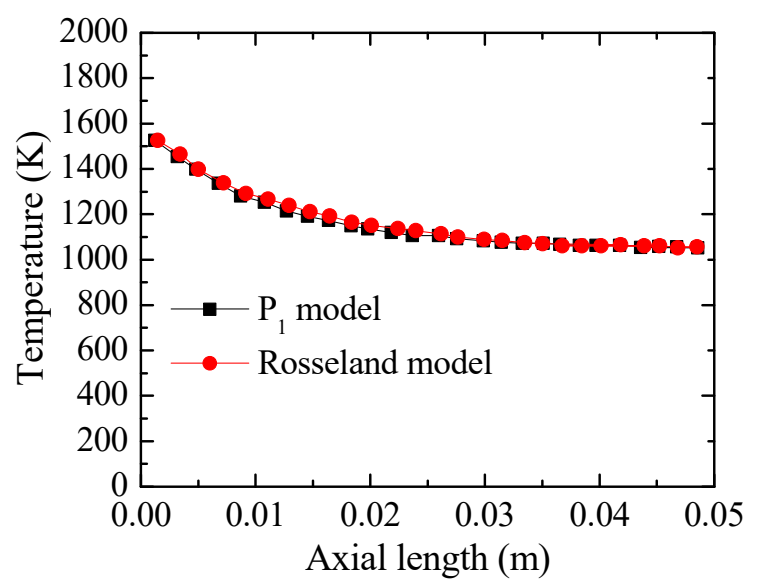

Figure 2. Temperature distribution in the proposed reactor compared to a conventional reactor [25] under $1600 \mathrm{~K}$ applied radiation heat flux on quartz glass with $5 \times 10^{-4} \mathrm{~kg} / \mathrm{s}$ mass flow and $1 \mathrm{~atm}$. This was computed with the proposed $\mathrm{P}_{1}$ radiation model and the Rosseland radiation approximation derived from [25].

\subsection{Grid Independent Tests}

Figure $3 \mathrm{~b}$ indicates the heat transfer along the cross-section and the scale of temperature. A grid-independent test was conducted on the mesh model at the beginning of the simulation process as shown in Figure 3a. Eleven meshes $(6816 ; 26,065 ; 58,017 ; 90,478 ; 118,168 ; 160,516 ; 284,912 ; 360,191$; 469,$243 ; 641,599 ; 42,302$ ) were modeled under $1600 \mathrm{~K}, 11 \times 10^{4} \mathrm{~kg} / \mathrm{s}$ and $1 \mathrm{~atm}$ (Table 2). From Figure 3c,d and Table 2, the change in temperature corresponding to the change in the number of cells and the percentage change were computed and it was observed that as the cells increased from 19,249 to 125,000 , the average outlet temperature decreased. However, as change in cells increased from 125,000 to 300,000 , the percentage change became nearly constant (Figure 3d). However, as the change in cells increased further from 175,000 to 300,000 the percentage change became perfectly constant. This implied that the increase in cell number did not affect the temperature. Based on the result, it was possible to select cell numbers between 160,516 and 942,302 ( $N, 160,516 \leq N \leq 942,302)$, however, 284,912 mesh type was selected for this study.

Table 2. Percentage change in temperature with number of cells.

\begin{tabular}{cccc}
\hline $\boldsymbol{\Delta} \boldsymbol{N}$ & $\boldsymbol{\Delta} \boldsymbol{T}$ & $\frac{\Delta \boldsymbol{T}}{\Delta \boldsymbol{N}} \cdot 100 \%$ & Rounding to Three Digits \\
\hline 19,249 & 21.6 & 0.1122 & 0.112 \\
31,952 & 7.7 & 0.0241 & 0.024 \\
32,461 & 3.2 & 0.00985 & 0.01 \\
27,690 & 1 & 0.0036 & 0.004 \\
42,348 & 1.3 & 0.0031 & 0.003 \\
124,396 & 1.6 & 0.0013 & 0.001 \\
75,279 & 0.6 & 0.000797 & 0.001 \\
109,052 & 0.2 & 0.000183 & 0 \\
172,356 & 0.5 & 0.0002900 & 0 \\
300,703 & 0.6 & 0.0001900 & 0 \\
\hline
\end{tabular}




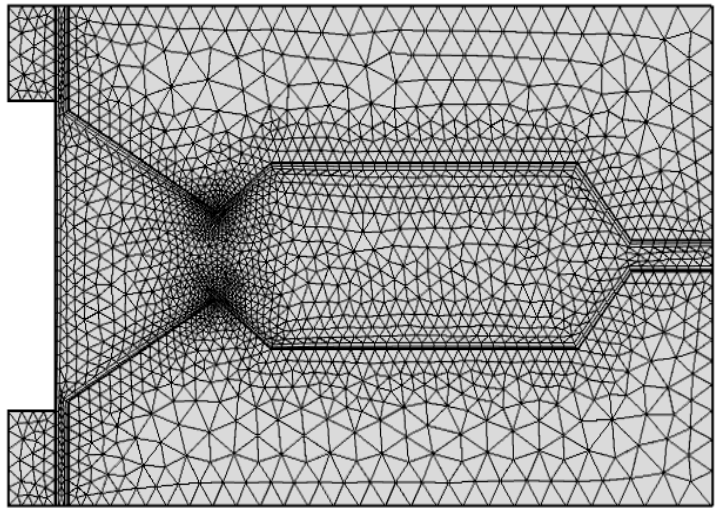

(a)

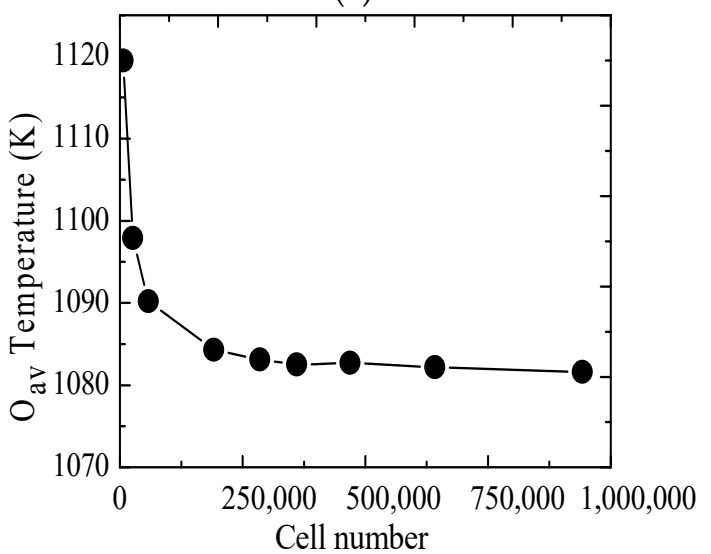

(c)

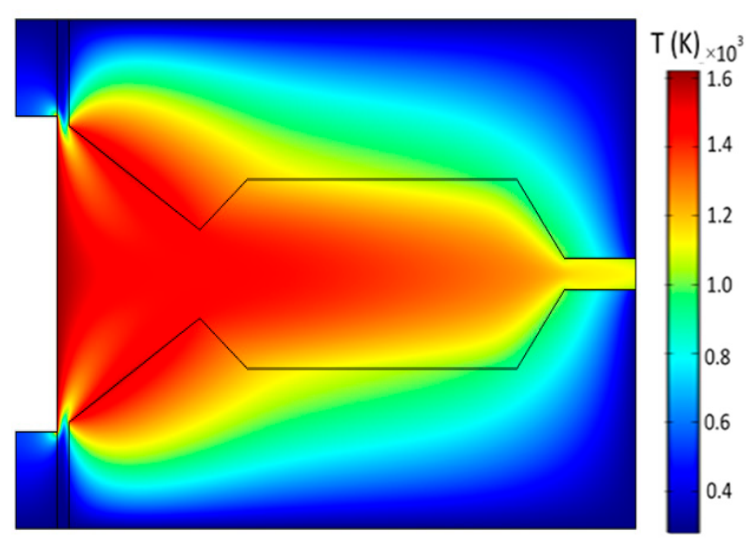

(b)

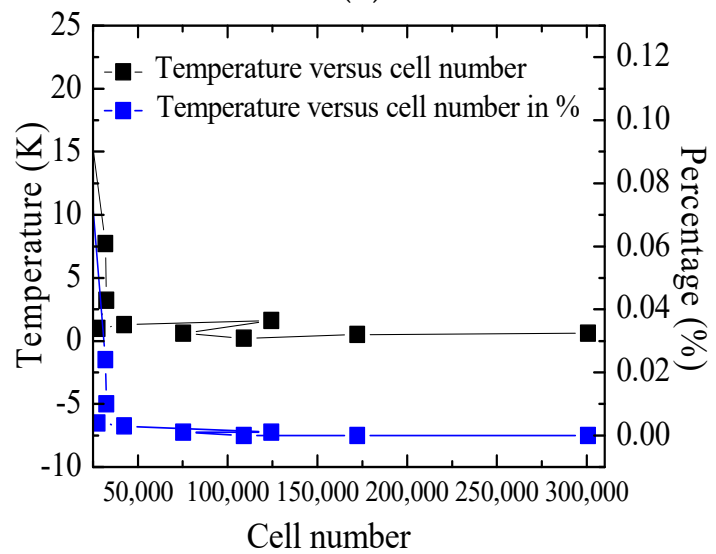

(d)

Figure 3. Grid independent analysis at $1600 \mathrm{~K}$ applied radiation heat flux on quartz glass with $11 \times 10^{-4} \mathrm{~kg} / \mathrm{s}$ mass flow rate of fluid inlet velocity and $1 \mathrm{~atm}$ in the proposed heat storage reactor: (a) mesh, (b) temperature distribution in the reactor, (c) temperature distribution with different cell number and (d) the percentage change of temperature to the change of number of cells.

\section{Result and Discussion}

\subsection{General Heat and Fluid Flow}

The present study proposed a syngas reactor (Figure 1) that received concentrated solar directly through a quartz glass window [38-40] that was equivalent to $1600 \mathrm{~K}$ radiation temperature and utilized the boundaries indicated in Table 1 . The radiation temperature coming from the source entered the reactor through a quartz glass and directly impinged on the frustum. The wall or diffused surface was made up of FeCrAl with an emissivity coefficient of 0.7 . The incoming radiation flowed with low absorption to the cavity with increase in time, which led to increased absorption of heat flux and a temperature increase in the cavity. The fluid flowed through two opposite inlets, then diverged to the inner surface and converged at the center of the reactor axis. This diverging and converging flow of inlet fluid facilitated heat entry into the inner portions of the cavity. As fluid flow continued towards the outlet region, there was no return flow to the aperture. This resulted in no deposition of solids around the quartz window, thus enhancing aerodynamic curtain and increasing the velocity towards the outlet. This is also attributed to decrease in the cross-section and increase in thermal expansion. The heat flux that was maximum at the quartz glass decreased slightly at the end of the cross-section. As the fluid flowed along the cross-section of the reactor, it was observed that the fluid-absorbed flux was heated. Also, there was loss of heat around the radiation inlet region and the aperture region, and conduction and convective heat losses occurred due to heat transfer to the environment. 


\subsection{Impact of the Insulated Layer Thickness and Insulator Type on the Outlet Tube Design}

Proper design is critical for the development of a reactor and its heat transfer effectiveness. The different parts for the assembly of a reactor, such as the receiver and aperture, and the parameters such as cavity width, height and inlet and outlet diameters are important in achieving optimal outlet temperature for efficient harnessing of solar radiation. Other factors, such as wall material selection and insulation, play a role in a syngas production reactor and are also very important for achieving optimal outlet temperature. From Figure $4 \mathrm{c}, \mathrm{d}$, it can be seen that maximum average outlet temperature was attained when the tube was insulated with $\mathrm{Al}_{2} \mathrm{O}_{3}$. This implied that the physical property of the insulator played a vital role in the thermal performance of a reactor; as the result, aluminum oxide was found to be important for both uniform temperature distribution of the reactor and the average outlet temperature. However, Figure $4 \mathrm{~b}$ revealed that maximum density was attained when the tube was insulated with $\mathrm{FeCrAl}$, and the latter exhibited the lowest average outlet temperature (Figure 4c,d). From Figure $4 \mathrm{a}$, it can be observed that the thickness of the boundary layer increased with increase in average outlet temperature. This increment in outlet temperature was maximum when the thickness of the outlet tube layer was $50 \mathrm{~mm}$. However, greater layer thickness caused the heat to be stored in between the particles of the walls of the insulator. This resulted in the intended temperature not reaching the outlet tube, thus, leading to possible damage of the reactor.

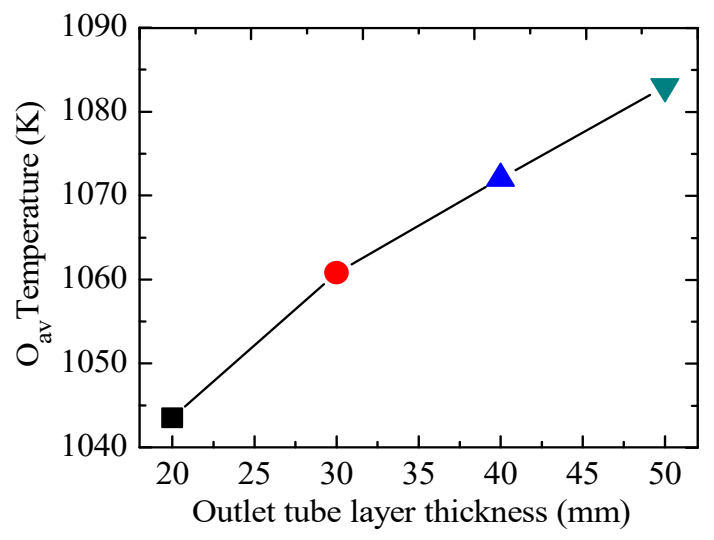

(a)

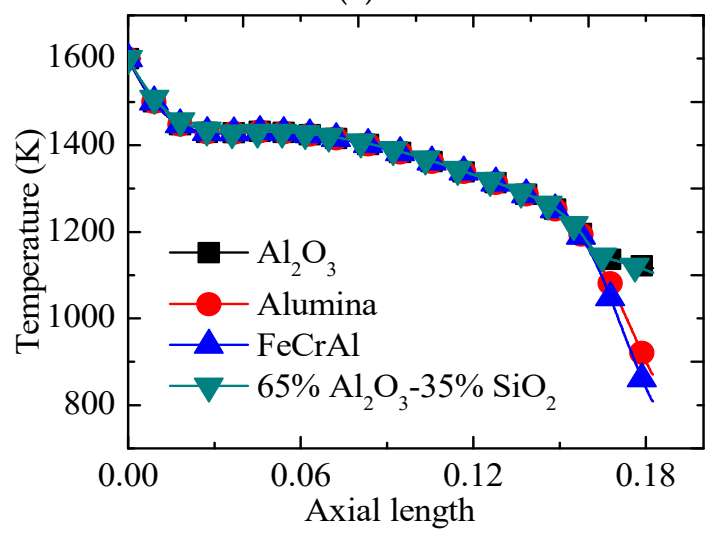

(c)

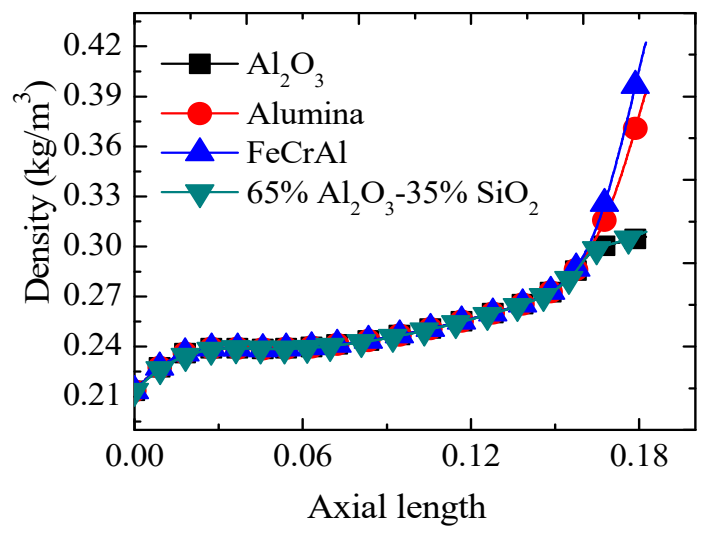

(b)

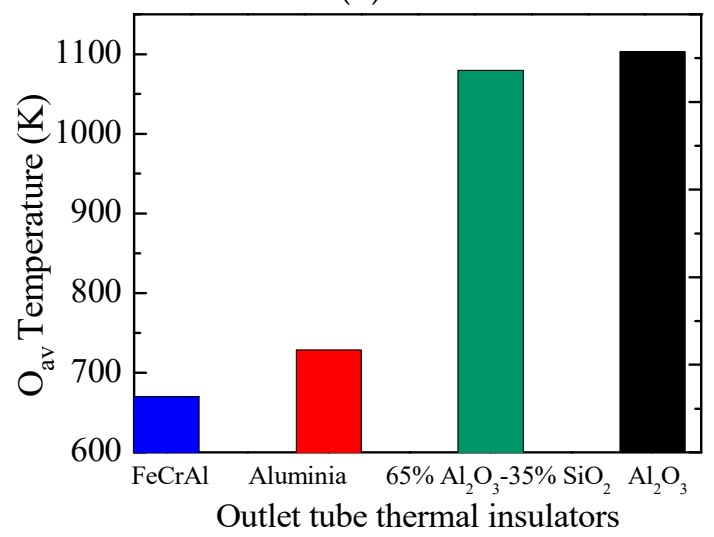

(d)

Figure 4. Temperature distribution at $1600 \mathrm{~K}$ applied radiation heat flux on quartz glass with $11 \times 10^{-4} \mathrm{~kg} / \mathrm{s}$ mass flow rate of fluid inlet velocity and $1 \mathrm{~atm}$ for different boundary materials in the proposed heat storage reactor: (a) average outlet $\left(\mathrm{O}_{\mathrm{av}}\right)$ temperature as a function of outlet tube thickness, (b) density as a function of thermal insulator axial length, (c) temperature as a function of thermal insulator axial length and (d) average outlet temperatures for different boundary materials. 


\subsection{Impact of Wall Materials on Reactor Thermal Performance}

Different wall materials were computed and analyzed for their impact on the thermal performance of the proposed reactor (Figure 5). Using the COMSOL material library, the computation was done by comparing wall materials: FeCrAl alloy (with a melting point close to $1773 \mathrm{~K}$ (density of $7100 \mathrm{~kg} / \mathrm{m}^{3}$, thermal conductivity of $35 \mathrm{~W} / \mathrm{m} \cdot \mathrm{K}$ at $1673 \mathrm{~K}$, heat capacity of $0.8 \mathrm{kJJ} / \mathrm{kg} \cdot \mathrm{K}$ at $1673 \mathrm{~K}$ and emissivity of 0.7 ); zirconia $\left(\mathrm{ZrO}_{2} \mathrm{eY}_{2} \mathrm{O}_{3}\right.$ ) (density of $5700 \mathrm{~kg} / \mathrm{m}^{3}$, thermal conductivity of $2.2 \mathrm{~W} / \mathrm{m} \cdot \mathrm{K}$ at $298 \mathrm{~K}$, heat capacity of $0.5 \mathrm{~kJ} / \mathrm{kg} \cdot \mathrm{K}$ at $298 \mathrm{~K}$ and can withstand temperatures up to $1873 \mathrm{~K}$ ) [36]; and $3 \mathrm{Al}_{2} \mathrm{O}_{3}-2 \mathrm{SiO}_{2}$ (mullite) solid $\left(36 \%\right.$ porosity and temperature dependent density $\rho(T)=\left(\rho(T(1 / \mathrm{K}))\left(\mathrm{kg} / \mathrm{m}^{3}\right)\right.$, thermal conductivity $\mathrm{k}(T)=\mathrm{k}(T(1 / \mathrm{K}))(\mathrm{W} /(\mathrm{m} \cdot \mathrm{K}))$ and a heat capacity of $0.84 \mathrm{~kJ} / \mathrm{kg} \cdot \mathrm{K}$.

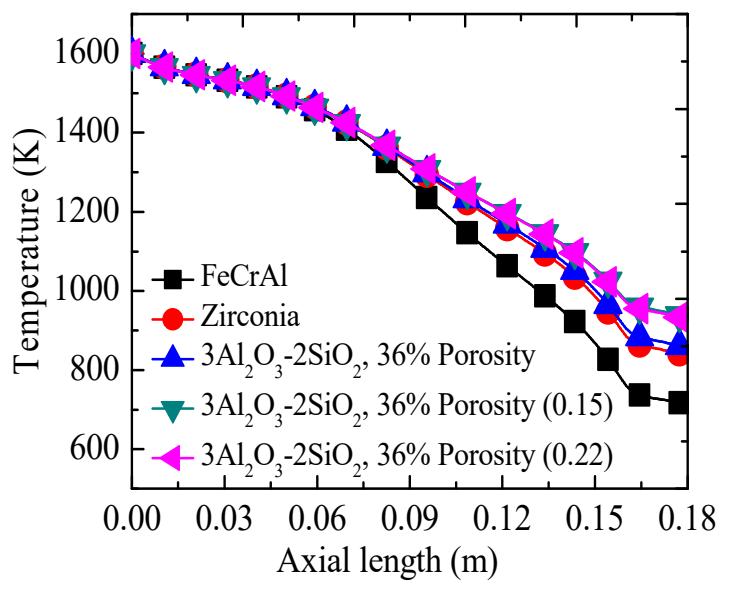

(a)

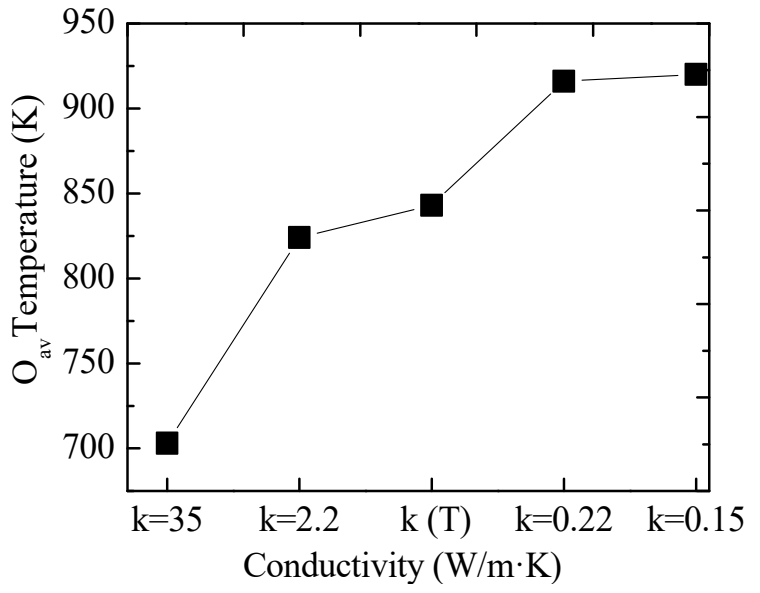

(b)

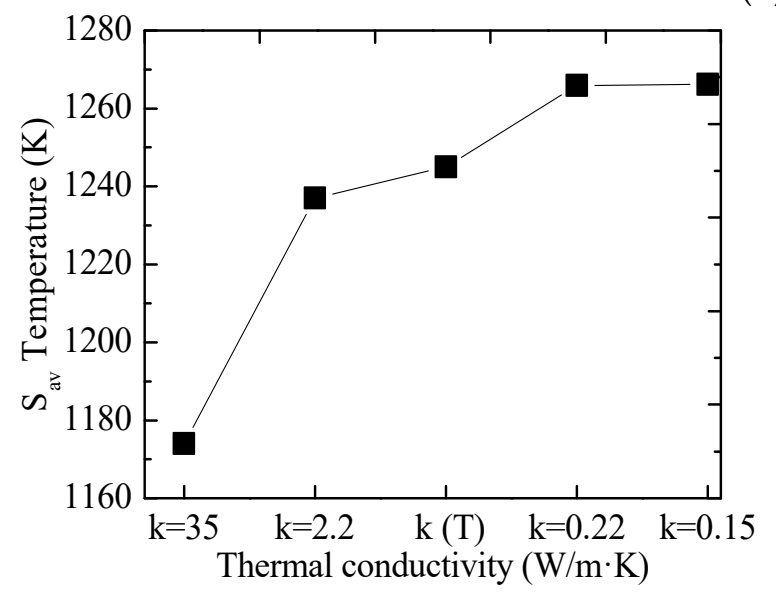

(c)

Figure 5. Temperature distribution at $1600 \mathrm{~K}$ radiation temperature applied on quartz glass with $11 \times 10^{-4} \mathrm{~kg} / \mathrm{s}$ mass flow rate and $1 \mathrm{~atm}$ for the proposed reactor: (a) temperature distribution for different wall made material, $(\mathbf{b})$ the average outlet $\left(\mathrm{O}_{\mathrm{av}}\right)$ temperature for different $\mathrm{k}$ values and (c) average surface $\left(S_{a v}\right)$ temperature of the reactor for different $k$ values. 
Figure 5a reveals that the wall made from $\mathrm{FeCrAl}$ had the lowest thermal performance when compared with the other wall materials. By keeping the other parameters constant and evaluating the thermal conductivity function of $\mathrm{k}(T)=\mathrm{k}(T(1 / \mathrm{K}))(\mathrm{W} /(\mathrm{m} \cdot \mathrm{K}))$ using $\mathrm{k}=0.22$ and $\mathrm{k}=0.15$ from the wall made from $3 \mathrm{Al}_{2} \mathrm{O}_{3}-2 \mathrm{SiO}_{2}$, the result indicated that both the average outlet and average surface temperatures were highest at $\mathrm{k}=0.15>\mathrm{k}=0.22>\mathrm{k}(T)$ for all wall materials, but all wall materials had different thermal conductivities Figure $5 b$,c. Therefore, the thermal performance of the reactor was critically affected by the wall material thermal conductivity. Overall, wall material with high thermal conductivity, such as $\mathrm{FeCrAl}$ alloy, had the lowest thermal performance. It is important to mention that wall materials with high thermal performance may be susceptible to high heat loss, this is because conduction heat is directly proportional to thermal conductivity, which leads to high heat loss in the external insulator domain. This occurrence has a negative impact on heat storage that may lead to damage of the reactor. Thus, in this study, FeCrAl alloy was used as the wall material due to the fact that all other wall materials considered in this present study did not pass through laboratory analyses in previous studies, and for the purpose of this study, their properties were assumed (see Section 2.3). In the case of $\mathrm{FeCrAl}$ alloy, Bellouard et al. [36] experimentally verified $\mathrm{FeCrAl}$ alloy in a directly irradiated solar chemical reactor for hydrogen and syngas production, and revealed that a material thickness of $0.3 \mathrm{~cm}$ could withstand up to $1873 \mathrm{~K}$. Therefore, the simulation result in this current study highlighted that there are other wall materials that have good thermal performance for the production of a syngas reactor. However, these materials will require experimental verification.

\subsection{Impact of Inlet Tube Insulation}

From Figure 6a, it is seen that keeping other input parameters constant and varying the location of the fluid inlet tubes and their insulation condition alters the temperature distribution in the reactor. As the inlet tubes were located immediately at the applied heat source boundary and its insulated material elongated above the quartz glass, as shown in Figure $6 \mathrm{~d}$, it was found that the temperature distribution was more uniform than the inlet tubes located below the quartz glass edges at opposite ends. This suggests that the inlet tubes located near the heat source boundary prevented the deposition of solid particles, hence, hindering heat transfer into the reactor and consequently affecting the thermal performance of the reactor. From Figure $6 b, c$, both average surface outlet and average outlet temperatures were greater for inlets at the quartz glass edge than those below the quartz glass edge. This is because, as fluid flows through the radiation inlet region, besides avoiding solid deposition around the frustum, the fluid takes radiation away from the inlet region to the cavity. From Figure 6a, as the fluid flow increased beyond $8 \times 10^{-4} \mathrm{~kg} / \mathrm{s}$, the average surface temperature decreased, whereas, the average outlet temperature increased, as shown in Figure 6b. From Figure 6d, it can be easily seen that there was no temperature concentration at the quartz boundary, but in Figure $6 \mathrm{~d}$, note that there was concentrated temperature around the quartz glass boundary, which was not evacuated to the reactor and exposed for reirradiation. It is possible to conclude that both inlet locations at the quartz glass edges and insulation above the opposite ends of the quartz glass of a reactor are important for uniform temperature distribution and enhancement of high heat transfer into the reactor cavity, with the latter factor being the most important. 


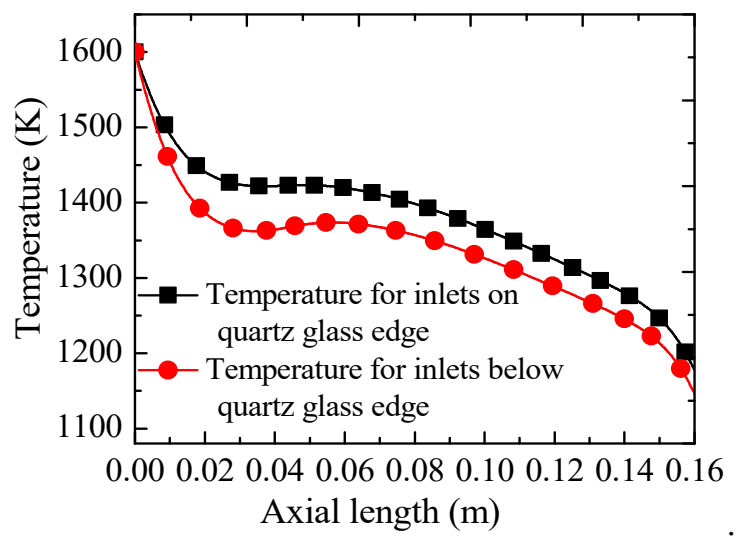

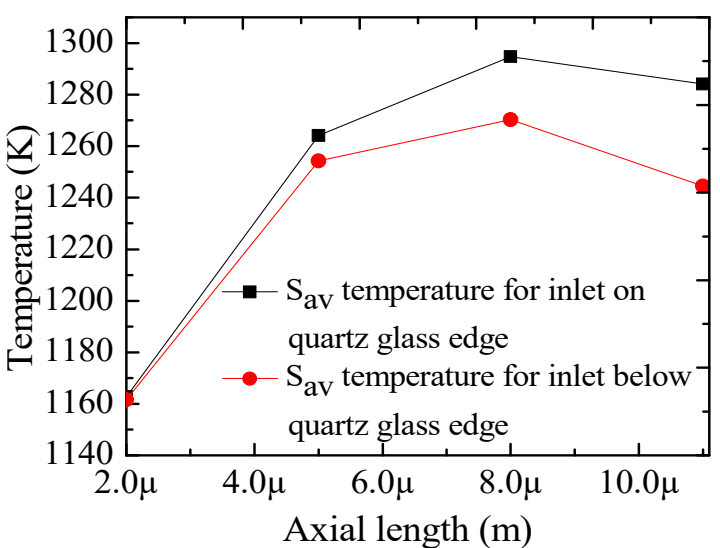

(b)

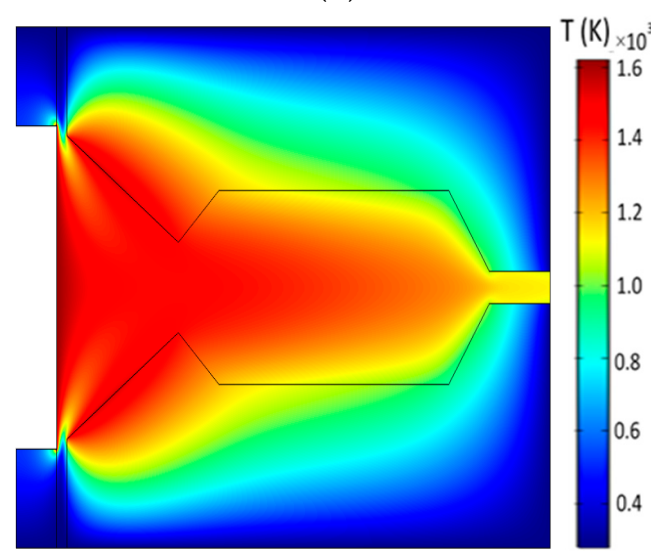

(d)

(a)

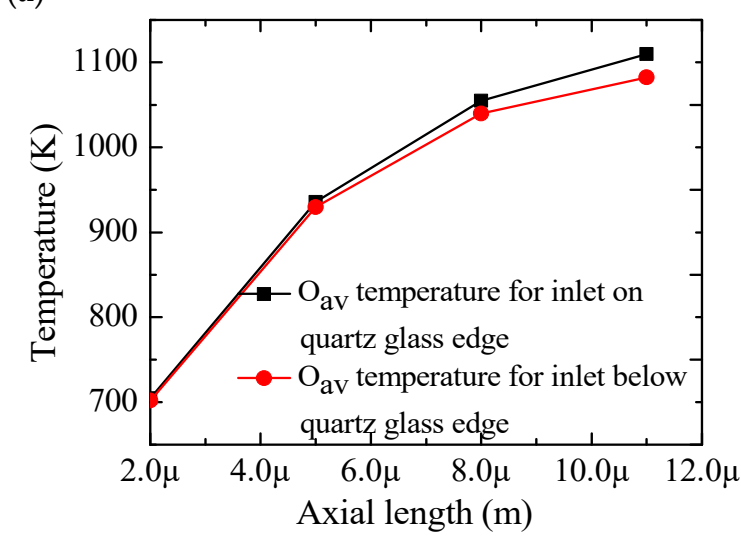

(c)

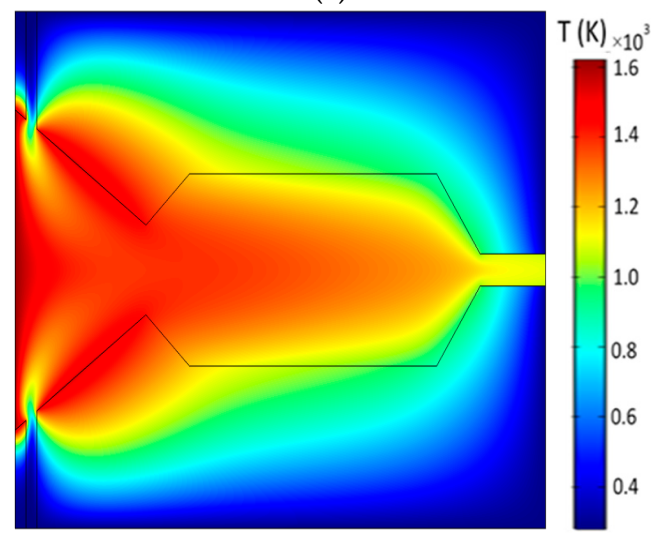

(e)

Figure 6. Temperature distribution at $1600 \mathrm{~K}$ applied radiation temperature on quartz glass with $11 \times 10^{-4} \mathrm{~kg} / \mathrm{s}$ mass flow rate and $1 \mathrm{~atm}$ for the proposed reactor: (a) temperature distribution for the inlet tube located on and below the quartz glass edge, $(\mathbf{b})$ average surface $\left(\mathrm{S}_{\mathrm{av}}\right)$ temperature for the inlet tube located at and below the quartz glass edge, $(\mathbf{c})$ average outer $\left(\mathrm{O}_{\mathrm{av}}\right)$ tube temperature for the inlet tube located at and below quartz glass edge, (d) axial temperature distribution for the inlet at the quartz glass edge and (e) axial temperature distribution for the inlet below the quartz glass edge.

\subsection{Impact of Mass Flow Rate on Thermal Performance}

From Figure 7a, as the mass flow rate increased from $5 \times 10^{-4} \mathrm{~kg} / \mathrm{s}$ to $14 \times 10^{-4} \mathrm{~kg} / \mathrm{s}$, the cavity temperature distribution increased but the temperature drop increased from 0 to $0.02 \mathrm{~m}$ around radiation inlet region and $0.02 \mathrm{~m}$ to $0.05 \mathrm{~m}$ in the aperture region. When the flow rate increased the dropping temperature in the frustum region, the cavity and outlet temperatures increased. This suggests 
that more mass flowed into the cavity and more heat was transferred to the cavity; as a result, the cavity heated because of heat absorption by the fluid in the cavity. Consequently, convective heat flux increased, but further increase in mass flow rate resulted in increased velocity and collision of particles from opposite sides of the inlet tubes, which developed kinetic energy that was later converted to heat. The development of kinetic energy led to the presence of more heat around the frustum region, thereby increasing instability around this region, as illustrated in Figure 7a. However, as flow rate was $\leq 5 \times 10^{-4} \mathrm{~kg} / \mathrm{s}$, the thermal performance was uniform but lower than the outlet temperature, although for this current study, $11 \times 10^{-4} \mathrm{~kg} / \mathrm{s}$ was selected to absorb the outlet temperature (Figure 7a). From Figure $7 \mathrm{~b}$, as the temperature applied through the quartz glass increased, the cavity and the outlet temperatures increased.

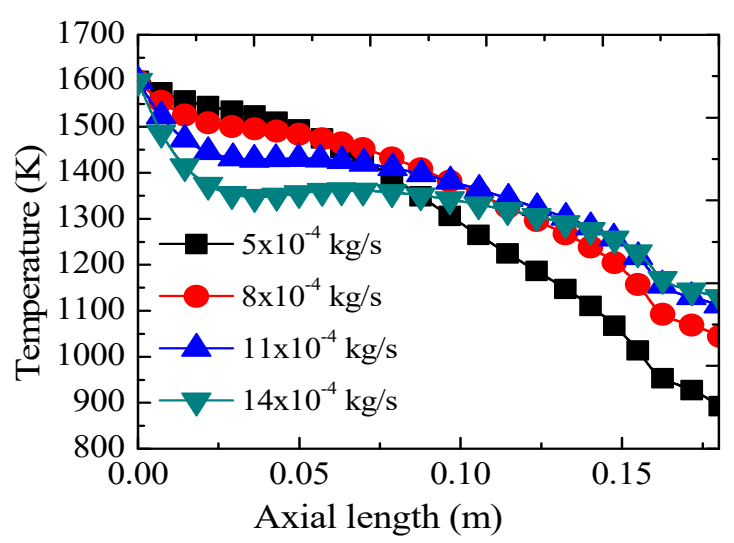

(a)

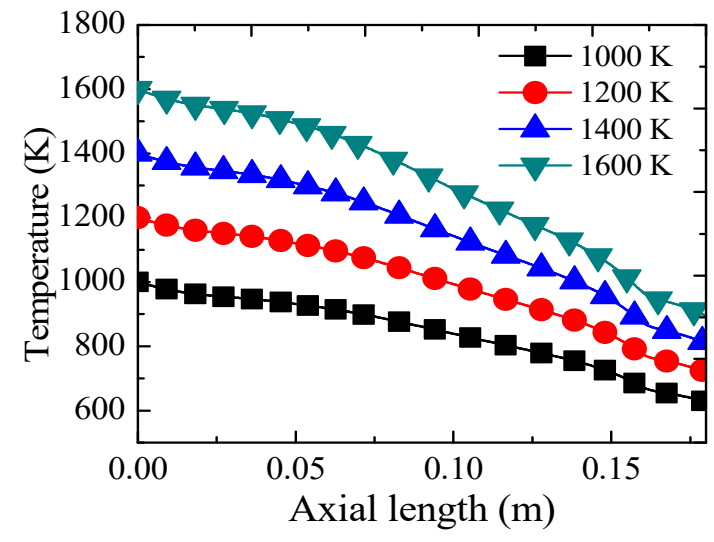

(b)

Figure 7. (a) Temperature as a function of different mass flow rates at $1 \mathrm{~atm}$ and (b) temperature as a function of axial length at $5 \times 10^{-4} \mathrm{~kg} / \mathrm{s}$ and $1 \mathrm{~atm}$.

\subsection{Impact of Thermal Performance on Inlet Condition}

From Figure 8a, the distribution temperature was more uniform for the inlet on the top of the frustum $(0 \mathrm{~cm})$. This was attributed to low reirradiation and less sedimentation of solid particles that affected the thermal performance of the reactor and as the result, more incident flux was absorbed by the gas inlet position in this region.

However, the inlet tubes located far from the top of the frustum $(0.5 \mathrm{~cm}$ and $1.25 \mathrm{~cm})$ had a high drop in temperature and high reirradiation. As a consequence, the cavity temperature and the average outlet temperature were low. In Figure 8 b, maximum velocity occurred at $0 \mathrm{~cm}$ or at the top of the inlet region because there was high thermal performance and low solid deposition in this region, which might be a factor for reducing velocity. Comparing the three fluid inlet locations of the reactor in Figure $7 \mathrm{c}$, it was found that uniform heat flux and magnitude of heat flux occurred around the quartz glass edge inlet location on the frustum. In Figure 8d, there was high conduction heat in the frustum at the radiation inlet 0 to $0.03 \mathrm{~m}$ regions, and aperture regions from 0.03 to $0.05 \mathrm{~m}$. This was possibly due to the fact that high thermal performance would affect the wall region of the frustum that caused conduction heat loss to the wall material. In Figure $8 \mathrm{a}-\mathrm{c}$, it was observed that when the location of the fluid inlets was far from the quartz horizontal, the radiation loss increased and thermal performance of the cavity decreased. This was due to concentrated re-irradiated heat and was thus exposed to conduction loss and convective heat transfer to the environment. Therefore, the appropriate fluid inlet location was the top region of the frustum. The heat transfer at different inlet locations of the quartz glass edge of the reactor is shown in Figure 8e,f. 


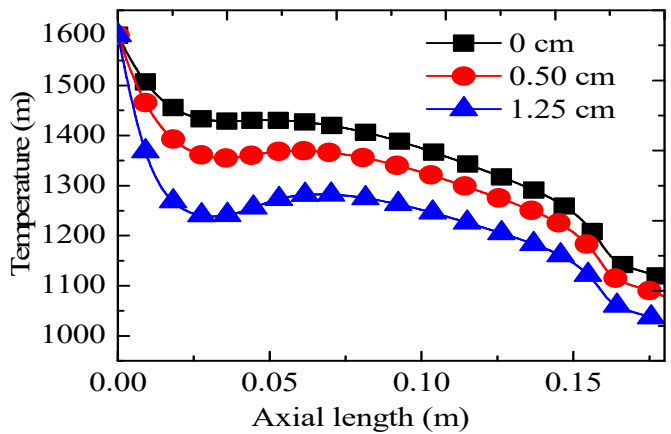

(a)

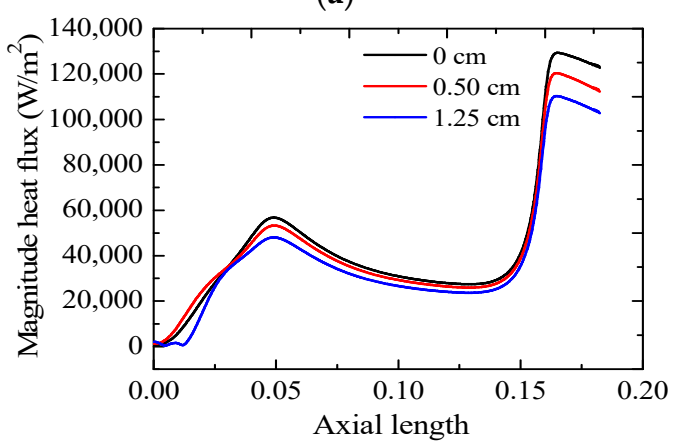

(c)

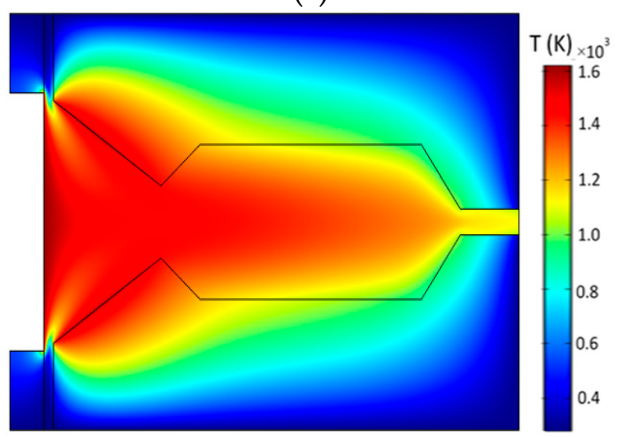

(e)

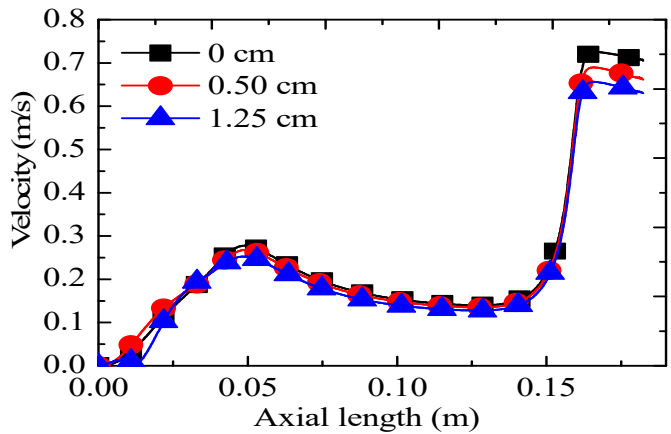

(b)

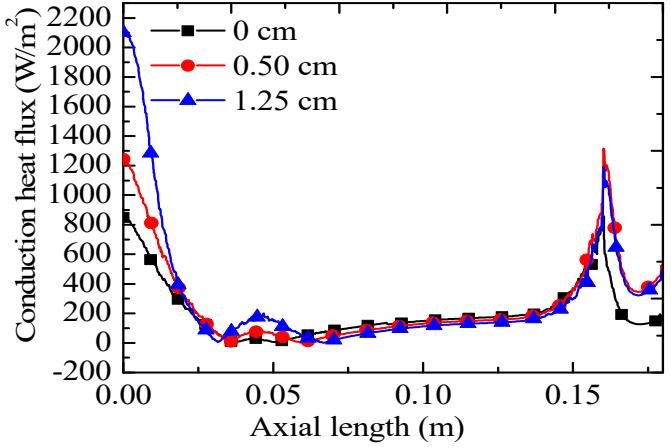

(d)

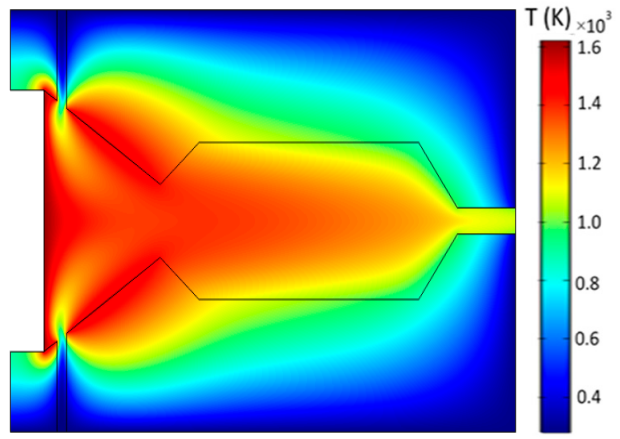

(f)

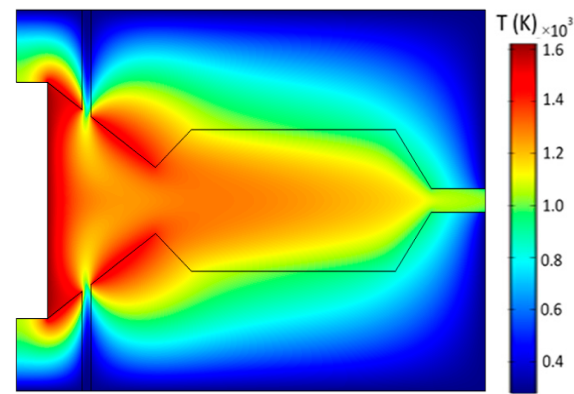

(g)

Figure 8. Effect of carrier gas inlet position on the frustum starting from the top, at $1600 \mathrm{~K}$ applied radiation heat flux on quartz glass with $11 \times 10^{-4} \mathrm{~kg} / \mathrm{s}$ mass flow rate of fluid inlet velocity and 1 atm in the proposed heat storage reactor: (a) temperature distribution, (b) velocity distribution, (c) magnitude of heat flux flow distribution, (d) conduction heat transfer, (e) heat transfer for the inlet at the quartz glass edge, (f) heat transfer for the inlet located $0.5 \mathrm{~cm}$ below the quartz glass edge and $(\mathrm{g})$ heat transfer for the inlet located $1.25 \mathrm{~cm}$ below the quartz glass edge. 


\subsection{Instantaneous Temperature Distribution}

As time increased, the absorbed temperature inside the cavity increased (Figure 9). From Figure 9a, as time increased from 10 to $90 \mathrm{~min}$, the concentrated flux around the frustum started to distribute inside the cavity, temperature distribution increased and attained maximum at $90 \mathrm{~min}$. The average surface temperature and average outlet temperature increased from 600 to $3000 \mathrm{~s}$ (Figure 9b,d). However, from 3000 s onwards, the average outlet and average surface temperature became constant. This indicates that effective absorption took place at 3000 to $5400 \mathrm{~s}$ (Figure 9c,d). As the temperature distribution in the cavity increased with time, the outlet temperature increased.

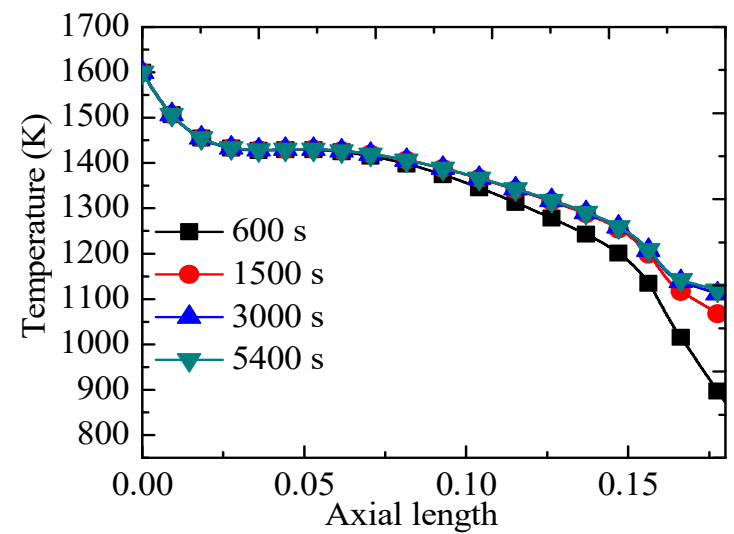

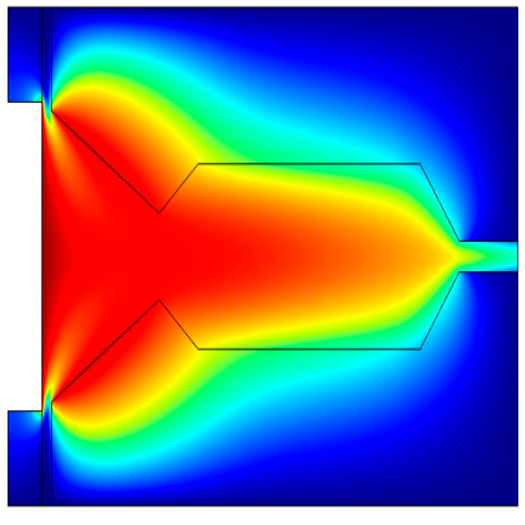

(b)

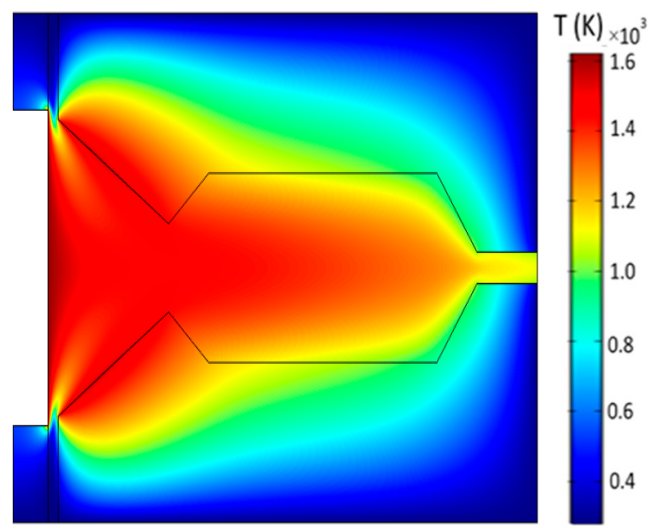

(d) (a)

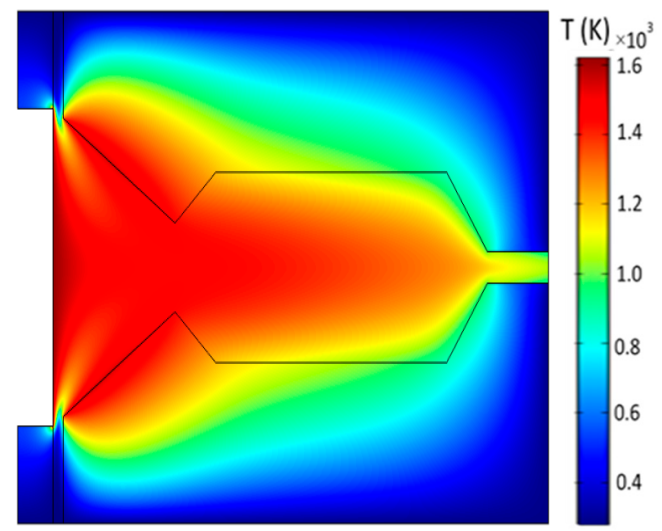

(c)

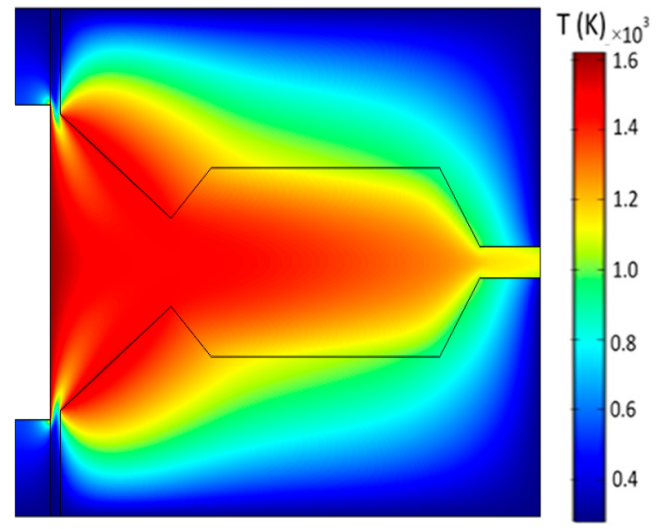

(e)

Figure 9. The distribution of temperature (a) at $600 \mathrm{~K}$ applied radiation heat flux on quartz glass with $11 \times 10^{-4} \mathrm{~kg} / \mathrm{s}$ mass flow rate of fluid inlet velocity and $1 \mathrm{~atm}$ in the proposed heat storage reactor. Effective absorption at $600 \mathrm{~s}$ (b), $1500 \mathrm{~s}$ (c), $3000 \mathrm{~s}$ (d) and $5400 \mathrm{~s}$ (e). 


\section{Conclusions}

A syngas production reactor for solar energy application was developed and its thermal performance evaluated. A $\mathrm{P}_{1}$ radiation approximation model and a shallow channel approximation coupling fluid flow were used to analyze the applied radiation intensity, as well as the temperature distribution in the reactor. It was found that the fluid inlet location, mass flow rate, wall material, layer thickness and insulator type for the outlet tube had significant effect on the thermal performance of the proposed reactor. Locating the fluid inlets at the quartz glass edge and insulation above the quartz glass edge for inlet tubes prevented reirradiation, thereby increasing the internal temperature distribution and the average outlet temperature of the reactor. Locating the fluid inlet tubes near the applied heat source facilitated the migration of heated particles into the internal part of the reactor. This inlet tube location was important in preventing particle sedimentation around the quartz glass edges. However, locating the inlet tubes far from the applied radiation heat source increased reirradiation due to sedimentation of particles near the heat source edge, which affected the uniform temperature distribution along the axial length of the reactor. In situating the inlet tubes near the quartz glass edge, the insulator must be installed above the opposite ends of the quartz glass edge, as this will hinder radiation loss and facilitate heat transfer towards the inner cavity of the reactor. Applying a $1600 \mathrm{~K}$ radiation temperature to the quartz glass and $11 \times 10^{-4} \mathrm{~kg} / \mathrm{s}$ mass flow on each inlet tube led to an average outlet temperature of $1097 \mathrm{~K}$ at end of the outlet tube. It was also possible to achieve radiation temperatures $>1200 \mathrm{~K}$ for cavity cross-sections $<0.18 \mathrm{~m}$. Furthermore, it was deduced that the wall material thermal conductivity was a dominant factor in achieving optimal thermal performance of the reactor. Moreover, high wall thermal conductivity led to high conduction heat loss, which consequently decreased the thermal performance of the reactor. An aluminum oxide-type insulator with $50 \mathrm{~mm}$ layer thickness applied at the boundary of the outlet tubes of the reactor produced an optimal maximum average outlet temperature and uniform distribution of temperature. For the outlet tube, a boundary layer thickness range of 50 to $55 \mathrm{~mm}$ was found to be appropriate for the thermal performance of the reactor. Further increase above this boundary layer thickness range damaged the reactor by increasing the accumulation of heat in between the inner boundary layers, which prevented transfer of heat to the outer insulation domain of the reactor. Mass flow rates between $4 \times 10^{-4}$ to $11 \times 10^{-4} \mathrm{~kg} / \mathrm{s}$ for each inlet achieved maximum outlet temperature and elicited good thermal performance. Overall, in achieving high-temperature flow inside the cavity, the reactor will be properly designed and the geometry of the reactor will be optimized.

Author Contributions: All authors contributed to the attainment of this work as follows: Formal analysis, Investigation, Data curation, Writing-original draft, Presentation data, Writing and review, Y.G.D.; Conceptualization, Methodology, Supervision, Validation and Funding acquisition, B.G.L. and Q.H.; Software, Z.J. and G.B.; Visualization, I.M.A. and T.H. All authors have read and agreed to the published version of the manuscript.

Funding: This work was funded by the National Natural Science Foundation of China (Nos. 51976044; 51950410590), China Postdoctoral Science Foundation Fund (2019M651284).

Acknowledgments: The authors appreciate the contributions of anonymous contributors in terms of their technical support in enhancing the quality of this work.

Conflicts of Interest: The authors declare no conflict of interest and the funders had no role in the design of the study; in the collection, analyses, or interpretation of data; in the writing of the manuscript, or in the decision to publish the results. 


\section{Nomenclature}

$\begin{array}{lll}c_{p} & \text { Specific heat capacity } & \mathrm{J} /(\mathrm{kg} \cdot \mathrm{K}) \\ \mathrm{G} & \text { Incident radiation intensity } & \mathrm{W} / \mathrm{m}^{2} \\ \mathrm{~h} & \text { Thermal flux coefficient } & \mathrm{W} /\left(\mathrm{m}^{2} / \mathrm{K}\right) \\ \mathrm{I} & \text { Radiation intensity } & \mathrm{W} /\left(\mathrm{m}^{2} \cdot \mathrm{sr}^{-1}\right) \\ \mathrm{k} & \text { Thermal conductivity } & \mathrm{J} /(\mathrm{m} \cdot \mathrm{K}) \\ \mathrm{T} & \text { Temperature } & \mathrm{K} \\ \mathrm{n}_{\mathrm{r}} & \text { Refraction index } & - \\ \mathrm{P} & \text { Pressure } & \mathrm{Pa} \\ \mathrm{Q}_{\mathrm{rad}} & \text { Radiation heat source } & \mathrm{W} / \mathrm{m}^{3} \\ \mathrm{u} & \text { Velocity vector } & \mathrm{m} / \mathrm{s} \\ \mathrm{Greek} \mathrm{symbol} & & \\ \alpha_{p} & \text { Coefficient of thermal expansion } & 1 / \mathrm{K} \\ \varepsilon & \text { Emissivity } & - \\ \kappa & \text { Absorption constant } & 1 / \mathrm{m} \\ \mu & \text { Dynamic viscosity } & \mathrm{Pa} \cdot \mathrm{s} \\ \rho & \text { Fluid density } & \mathrm{kg} / \mathrm{m}^{3} \\ \sigma_{\mathrm{S}} & \text { Scattering coefficient } & 1 / \mathrm{m} \\ \sigma_{S B} & \text { Stefan-Boltzmann constant } & \mathrm{W} /\left(\mathrm{m}^{2} \cdot \mathrm{K}^{4}\right) \\ \Phi & \text { Scattering phase angle } & \mathrm{radian} \\ \Omega & \text { Solid angle } & \mathrm{Steradian}(\mathrm{sr})\end{array}$

\section{References}

1. Meier, A.; Ganz, J.; Steinfeld, A. Modeling of a novel high-temperature solar chemical reactor. Chem. Eng. Sci. 1996, 51, 3181-3186. [CrossRef]

2. Steinfeld, A.; Schubnell, M. Optimum aperture size and operating temperature of a solar cavity-receiver. Sol. Energy 1993, 50, 19-25. [CrossRef]

3. Lougou, B.G.; Han, D.; Zhang, H.; Jiang, B.; Anees, J.; Ahouannou, C.; Zhao, J.; Shuai, Y. Numerical and experimental analysis of reactor optimum design and solar thermal-chemical energy conversion for multidisciplinary applications. Energy Convers. Manag. 2020, 213, 112870. [CrossRef]

4. Adanez, J.; Abad, A.; Garcia-Labiano, F.; Gayan, P.; Luis, F. Progress in chemical-looping combustion and reforming technologies. Prog. Energy Combust. 2012, 38, 215-282. [CrossRef]

5. Graf, D.; Monnerie, N.; Roeb, M.; Schmitz, M.; Sattler, C. Economic comparison of solar hydrogen generation by means of thermochemical cycles and electrolysis. Int. J. Hydrog. Energy 2008, 33, 4511-4519. [CrossRef]

6. Veziroğlu, T.N.; Şahi, S. 21st Century's energy: Hydrogen energy system. Energy Convers. Manag. 2008, 49, 1820-1831. [CrossRef]

7. Le Duigou, A.; Borgard, J.-M.; Larousse, B.; Doizi, D.; Allen, R.; Ewan, B.C.; Priestman, G.H.; Elder, R.; Devonshire, R.; Ramos, V. HYTHEC: An EC funded search for a long term massive hydrogen production route using solar and nuclear technologies. Int. J. Hydrog. Energy 2007, 32, 1516-1529. [CrossRef]

8. Romero, M.; Steinfeld, A. Concentrating solar thermal power and thermochemical fuels. Energy Environ. Sci. 2012, 5, 9234-9245. [CrossRef]

9. Lougou, B.G.; Shuai, Y.; Zhang, H.; Ahouannou, C.; Zhao, J.; Kounouhewa, B.B.; Tan, H. Thermochemical $\mathrm{CO}_{2}$ reduction over $\mathrm{NiFe}_{2} \mathrm{O}_{4} @$ alumina filled reactor heated by high-flux solar simulator. Energy 2020, 197, 117267. [CrossRef]

10. Kodama, T.; Gokon, N. Thermochemical cycles for high-temperature solar hydrogen production. Chem. Rev. 2007, 107, 4048-4077. [CrossRef]

11. Steinfeld, A.; Palumbo, R. Solar thermochemical process technology. Encyclopedia Phys. Sci. Technol. 2001, 15, 237-256.

12. Schunk, L.O.; Haeberling, P.; Wepf, S.; Wuillemin, D.; Meier, A.; Steinfeld, A. A receiver-reactor for the solar thermal dissociation of zinc oxide. J. Sol. Energy Eng. 2008, 130, 021009. [CrossRef]

13. Sturzenegger, M.; Nüesch, P. Efficiency analysis for a manganese-oxide-based thermochemical cycle. Energy 1999, 24, 959-970. [CrossRef] 
14. Bellan, S.; Alonso, E.; Gomez-Garcia, F.; Perez-Rabago, C.; Gonzalez-Aguilar, J.; Romero, M. Thermal performance of lab-scale solar reactor designed for kinetics analysis at high radiation fluxes. Chem. Eng. Sci. 2013, 101, 81-89. [CrossRef]

15. Gardon, R. An instrument for the direct measurement of intense thermal radiation. Rev. Sci. Instrum. 1953, 24, 366-370. [CrossRef]

16. Gómez, F.; Gonzalez-Aguilar, J.; Romero, M. Experimental 3D flux distribution of a 7 kWe-solar simulator. In Proceedings of the Proc. SolarPACES, Granada, Spain, 20-23 September 2011; pp. 20-23.

17. Müller, R.; Haeberling, P.; Palumbo, R.D. Further advances toward the development of a direct heating solar thermal chemical reactor for the thermal dissociation of ZnO (s). Sol. Energy 2006, 80, 500-511. [CrossRef]

18. Ackermann, S.; Takacs, M.; Scheffe, J.; Steinfeld, A. Reticulated porous ceria undergoing thermochemical reduction with high-flux irradiation. Int. J. Heat. Mass. Transf. 2017, 107, 439-449. [CrossRef]

19. Wang, M.; Siddiqui, K. The impact of geometrical parameters on the thermal performance of a solar receiver of dish-type concentrated solar energy system. Renew. Energy 2010, 35, 2501-2513. [CrossRef]

20. Suter, S.; Steinfeld, A.; Haussener, S. Pore-level engineering of macroporous media for increased performance of solar-driven thermochemical fuel processing. Int. J. Heat. Mass. Transf. 2014, 78, 688-698. [CrossRef]

21. Wu, Z.; Caliot, C.; Flamant, G.; Wang, Z. Numerical simulation of convective heat transfer between air flow and ceramic foams to optimise volumetric solar air receiver performances. Int. J. Heat. Mass. Transf. 2011, 54, 1527-1537. [CrossRef]

22. Cheng, P. Two-dimensional radiating gas flow by a moment method. Am. Inst. Aeronaut. Astronaut. 1964, 2, 1662-1664. [CrossRef]

23. Cheng, P. Dynamics of a radiating gas with application to flow over a wavy wall. Am. Inst. Aeronaut. Astronaut. 1966, 4, 238-245. [CrossRef]

24. Wang, F.; Tan, J.; Yong, S.; Tan, H.; Chu, S. Thermal performance analyses of porous media solar receiver with different irradiative transfer models. Int. J. Heat. Mass. Transf. 2014, 78, 7-16. [CrossRef]

25. Wang, F.; Shuai, Y.; Tan, H.; Yu, C. Thermal performance analysis of porous media receiver with concentrated solar irradiation. Int. J. Heat. Mass. Transf. 2013, 62, 247-254. [CrossRef]

26. Zhang, H.; Lougou, B.G.; Pan, R.; Shuai, Y.; Wang, F.; Cheng, Z.; Tan, H. Analysis of thermal transport and fluid flow in high-temperature porous media solar thermochemical reactor. Sol. Energy 2018, 173, 814-824. [CrossRef]

27. Pan, R.; Lougou, B.G.; Shuai, Y.; Zhang, G.; Zhang, H. Heat Transfer Modeling of a High-Temperature Porous-Medium Filled Solar Thermochemical Reactor for Hydrogen and Synthesis Gas Production. J. Heat Transf. 2019, 141. [CrossRef]

28. Zhang, H.; Shuai, Y.; Lougou, B.G.; Jiang, B.; Wang, F.; Cheng, Z.; Tan, H. Effects of multilayer porous ceramics on thermochemical energy conversion and storage efficiency in solar dry reforming of methane reactor. Appl. Energy 2020, 265, 114799. [CrossRef]

29. Bellan, S.; Alonso, E.; Perez-Rabago, C.; Gonzalez-Aguilar, J.; Romero, M. Numerical modeling of solar thermochemical reactor for kinetic analysis. Energy Procedia. 2014, 49, 735-742. [CrossRef]

30. Lougou, B.G.; Shuai, Y.; Guohua, Z.; Chaffa, G.; Ahouannou, C.; Tan, H. Analysis of $\mathrm{H}_{2}$ and CO production via solar thermochemical reacting system of $\mathrm{NiFe}_{2} \mathrm{O}_{4}$ redox cycles combined with $\mathrm{CH}_{4}$ partial oxidation. Int. J. Hydrog. Energy 2018, 43, 5996-6010. [CrossRef]

31. Lougou, B.G.; Shuai, Y.; Zhang, J.; Huang, X.; Yuan, Y.; Tan, H. Syngas production by simultaneous splitting of $\mathrm{H}_{2} \mathrm{O}$ and $\mathrm{CO}_{2}$ via iron oxide $\left(\mathrm{Fe}_{3} \mathrm{O}_{4}\right)$ redox reactions under high-pressure. Int. J. Hydrog. Energy 2016, 41, 19936-19946.

32. Lougou, B.G.; Shuai, Y.; Chen, X.; Yuan, Y.; Tan, H.; Xing, H. Analysis of radiation heat transfer and temperature distributions of solar thermochemical reactor for syngas production. Front. Energy 2017, 11, 480-492. [CrossRef]

33. Lougou, B.G.; Shuai, Y.; Chaffa, G.; Xing, H.; Tan, H.; Du, H. Analysis of $\mathrm{CO}_{2}$ utilization into synthesis gas based on solar thermochemical $\mathrm{CH}_{4}$-reforming. J. Energy Chem. 2019, 28, 61-72. [CrossRef]

34. Peng, Z.; Doroodchi, E.; Moghtaderi, B. Heat transfer modelling in Discrete Element Method (DEM)-based simulations of thermal processes: Theory and model development. Prog. Energy Combust. Sci. 2020, 79, 100847. [CrossRef] 
35. Schrader, A.J.; Schieber, G.L.; Ambrosini, A.; Loutzenhiser, P.G. Experimental demonstration of a 5 kWth granular-flow reactor for solar thermochemical energy storage with aluminum-doped calcium manganite particles. Appl. Therm. Eng. 2020, 173, 115257. [CrossRef]

36. Bellouard, Q.; Rodat, S.; Abanades, S.; Ravel, S.; Frayssines, P.-É. Design, simulation and experimental study of a directly-irradiated solar chemical reactor for hydrogen and syngas production from continuous solar-driven wood biomass gasification. Int. J. Hydrog. Energy 2019, 44, 19193-19205. [CrossRef]

37. Shuai, Y.; Lougou, B.G.; Zhang, H.; Zhao, J.; Ahouannou, C.; Tan, H. Heat transfer analysis of solar-driven high temperature thermochemical reactor using NiFe Aluminate RPCs. Int. J. Hydrog. Energy 2020. [CrossRef]

38. Taylor, R.W.; Berjoan, R.; Coutures, J.P. Solar gasification of carbonaceous materials. Sol. Energy 1983, 30, 513-525. [CrossRef]

39. Belghit, A.; Daguenet, M. Study of heat and mass transfer in a chemical moving bed reactor for gasification of carbon using an external radiative source. Int. J. Heat. Mass. Transf. 1989, 32, 2015-2025. [CrossRef]

40. Flechsenhar, M.; Sasse, C. Solar gasification of biomass using oil shale and coal as candidate materials. Energy 1995, 20, 803-810. [CrossRef]

(C) 2020 by the authors. Licensee MDPI, Basel, Switzerland. This article is an open access article distributed under the terms and conditions of the Creative Commons Attribution (CC BY) license (http://creativecommons.org/licenses/by/4.0/). 